DOI: $10.14451 / 2.122 .100$

\title{
РАЗВИТИЕ СИСТЕМ УПРАВЛЕНИЯ ВЛАДЕЛЬЧЕСКИМИ РИСКАМИ КАК НЕОБХОДИМОЕ УСЛОВИЕ ЭКОНОМИЧЕСКОЙ УСТОЙЧИВОСТИ МАЛЫХ И СРЕДНИХ ПРЕДПРИЯТИЙ В РАМКАХ ЦИФРОВОЙ ЭКОНОМИКИ
}

(C) 2018 Хачатурян Михаил Владимирович

кандидат экономических наук, доцент кафедры Теории менеджмента и бизнес-технологий Российский Экономический Университет им. Г.В. Плеханова

117997, г. Москва, Стремянный пер., 36

E-mail:mike-hach@mail.ru

\section{(c) 2018 Айвазов Сергей Юрьевич}

кандидат экономических наук, доцент кафедры Общего и стратегического менеджмента Московский финансово-промышленный университет «Синергия»

105318, г. Москва, ул. Измайловский вал, 2

E-mail: usliga@yandex.ru

В статье проанализированы основные направления совершенствования систем управления владельческими рисками как необходимого условия экономической устойчивости малых и средних предприятий в рамках цифровой экономики. Описана специфика интеграции систем управления владельческими рисками и механизмов обеспечения экономической устойчивости в механизмы управления малыми и средними предприятиями. Охарактеризовано значение такой интеграции в процессе создания добавленной стоимости малых и средних предприятий. На основе проведенного анализа дается авторская оценка направлений развития систем управления владельческими рискам как основы обеспечения экономической устойчивости малых и средних предприятий.

Ключевые слова: система, развитие, управление, владельческие риски, основа, организация, экономическая устойчивость, малые и средние предприятия.

Роль, которую играют малые и средние предприятия в экономике как в развитых, так и в развивающихся странах, сложно переоценить, и поэтому их существование и выживание являются предметом озабоченности не только для органов государственного управления, но и для исследователей, занимающихся проблемами теории и практики менеджмента.

Как показывает зарубежная и отечественная статистика большое число малых и средних предприятий разоряется на протяжении первого года своего существования $[1,6]$. Основной задачей настоящего исследование является формирование представления об особенностях функционирования систем управления рисками малых и средних предприятий в целом и владельческими рисками в частности. Также задачей данной статьи является определение верности существующего в отечественной и зарубежной управленческой науке утверждения, что управление рисками является необходимым условием выживания и устойчивого развития малых и средних предприятий.

Цель исследования состояла в том, чтобы:
1) понять специфический характер среды функционирования малых и средних предприятий, который определяет основные уязвимости их систем управления;

2) изучить основные виды владельческих рисков, с которыми сталкиваются системы управления малыми и средними предприятиями;

3) понять, как владельцы и менеджеры малых и средних предприятий выстраивают системы управления владельческими рисками;

4) определить содержание понятия «управление владельческими рисками малого и среднего предприятия» и выявить его основные компоненты;

5) установить достоверность утверждения, что «управление рисками является определяющим для выживания и устойчивого развития малых и средних предприятий.

Как показывает практика малые и средние предприятия в силу размера своего бизнеса, недостаточности ресурсов и ограниченности доступа к инновационному рынку в целом сталкиваются с множеством видов рисков. 
Важно отметить, что управление рисками в малых и средних предприятиях сосредоточено в руках управляющих-собственников, и как правило, между элементами системы управления, ответственными за планирование и управление рисками нет системных связей. Поэтому в настоящем исследовании подчеркивается необходимость интеграции в рамках систем управления малыми и средними предприятиями систем управления владельческими рисками с элементами системы управления, ответственными за планирование и регулярное управления во избежание фатальных последствий для эффективности функционирования организаций.

По данным международной статистики на малые и средние предприятия приходится 99\% всех предприятий Сингапура, от 95\% до 99\% субъектов предпринимательства в странах Организации экономического сотрудничества и развития (ОЭСР). В Южной Африке 90\% малых и средних предприятий, обеспечивают $80 \%$ занятости в стране. В Индии доля малых и средних предприятий в ВВП страны составляет 8\%, на малые и средние предприятия также приходится $50 \%$ от общего объема экспорта промышленной продукции, $45 \%$ занятых в индийской промышленности и 95\% процентов всех промышленных предприятий [2].

В России на долю малого и среднего бизнеса в объеме ВВП приходится около 20\%. В 2017 г. наблюдался значительный прирост на $1,7 \%$ доли МСБ в ВВП России, что является положительной динамикой, при этом согласно Стратегии развития малого бизнеса, его доля в ВВП к 2030 г. должна вырасти до 40\% [3].

Таким образом, можно сказать, что микро -, малые и средние предприятия (Ммсп) играют важную роль в индустриализации, экономическом росте и устойчивом развитии экономики.

Очевидно, что малые и средние предприятия имеют решающее значение для роста любой экономики, поскольку они обладают потенциалом для создания рабочих мест, модернизации местных технологий, поощрения предпринимательства среди коренного населения и дальнейшей ассимиляции с крупномасштабными организациями. При этом специфика среды их функционирования такова, что такие предприятия могут выглядеть тривиальными или незначительными, но на самом деле они закладывают основу экономической устойчивой хозяйственной системы страны.
K числу преимуществ, создаваемых малыми и средними предприятиями для экономики страны, относятся:

- вклад в ускорение темпов роста производства товаров и услуг;

- создание рабочих мест с относительно небольшими капитальными затратами;

- сокращение неравенства в доходах;

- развитие рынка труда и сокращение масштабов бедности.

Они укрепляют как прямые, так и обратные связи между различными секторами экономики, тем самым интегрируя коренные народы в основное русло экономической жизни страны, а также создают перспективы для развития предпринимательских и управленческих компетенций в стране. Поскольку малые и средние предприятия являются двигателем экономического роста, их выживание и экономическая устойчивость имеют решающее значение не только для них, но и для роста и развития национальной хозяйственной системы в целом.

Микропредприятия, малые и средние предприятия работают в тех же деловых условиях, что и крупные корпорации, но без связанных с масштабом крупного бизнеса преимуществ, таких как достаточность капитала и квалифицированной рабочей силы. Они также сталкиваются с растущей конкуренцией и давлением, вызванными дерегулированием, либерализацией, глобализацией и сменой технологических укладов. Многие малые и средние предприятия, как правило, процветают в трудные времена из-за близости к своим клиентам, высокой способности к адаптации и гибкости, но в периоды стабильного развития становятся объектом воздействия факторов внешней среды, при условии отсутствия механизмов анализа и прогнозирования такого влияния. Важно также отметить, что в большинстве случаев система управления малыми и средними предприятиями, как правило, предполагает наличие единоличного собственника или партнерство под руководством собственников-менеджеров.

Очевидно, что владельцы-менеджеры малых и средних предприятий должны иметь в своем арсенале все инструменты управления, позволяющие им обладать всей полнотой информации о потенциальных рисках, сопровождающих функционирование организации, а также о мера и механизмах о выявления рисков, их смягчении и управления ими. В противном случае они 
могут пострадать от катастрофических последствий реализации рисковых событий.

Важно отметить, что ключевым элементом предотвращения таких последствий является интеграция систем управления владельческими рисками в повседневную деятельность систем управления организациями, что позволит бороться с неопределенностью деловой среды, гарантировать желаемый для владельца уровень доходности и обеспечивать выживание и экономическую устойчивость.

В современных условиях организации сталкиваются с всё возрастающим количеством и разнообразием внутренних и внешних рисков. Малые и средние предприятия не являются исключением. При этом определение компонентов риска в рамках систем управления малыми и средними предприятиями является более сложным из-за большой неоднородности и сложности в отделении бизнеса от владельца-менеджеpa.

Важно отметить, что наиболее насущными проблемами, стоящими перед малыми и средними предприятиями сегодня, являются:

- высокая текучесть кадров;

- нехватка квалифицированных кадров;

- высокий уровень информационных и технологических рисков;

- скорость рыночных изменений;

- ухудшение имиджа.

При этом авторы считают возможным определить основные виды рисков, с которыми сталкивается малый и средний бизнес как субъект предпринимательской деятельности:

- отсутствие профессионального подхода к управления организацией и избыточная зависимость от эффективности деятельности одного или двух человек в руководстве организацией;

- отсутствие рычагов влияния на финансовую инфраструктуру национальной экономики;

- интенсивная конкуренция;

- недостаточный уровень прибыли;

- слабость рычагов взыскании дебиторской задолженности;

- неспособность справиться с темпами технического прогресса;

- высокая текучесть кадров;

- низкий уровень взаимопонимания и взаимодействия между субъектами малого и среднего предпринимательства.

В глобальном масштабе малые и средние предприятия испытывают трудности с обеспе- чением финансирования из-за высокого уровня риска своей деятельности и недостаточного уровня доходности.

Риски малых и средних предприятий также могут быть классифицированы на основе их источников:

- риски, связанные с клиентами;

- риски поставщиков;

- риски, связанные с персоналом и т.д.

При этом следует подчеркнуть, что основные виды рисков, сопровождающие деятельность малых и средних предприятий являются побочным продуктом «финансовых рисков» и «предпринимательских рисков». Предпринимательские риски малых и средних предприятий включают такие категории риска, как управленческий риск (недостаточность управленческих знаний у владельцев и менеджеров, и т.д.), коммерческий риск (риск клиента и рыночный риск) и технологический риск (реализация технологии, НИОКР и т.д.).

Как правило, по термином малые и средние предприятия понимаются предприятия с высокой степенью риска, практически не имеющие структуры для управления рисками. При этом важно отметить, что малые и средние предприятия в логике функционирования ничем не отличаются от других организаций, но их размеры делают их уязвимыми к реализации рисковых событий, и они редко располагают достаточными ресурсами для найма специалистов по управлению рисками. Также очевидно, что малые и средние предприятия не обладают достаточными внутренними компетенциями для формирования стратегии оценки и управления рисками.

В большинству случаев малые и средние предприятия характеризуются отсутствием деловой и управленческой документация, недостаточной подготовкой персонала, отсутствием соответствующих навыков для принятия управленческих решений у владельцев и менеджеров, недостаточным потенциалом для управления рисками. Также малые и средние предприятия особенно страдают от плохого планирования, подверженности колебаниям денежных потоков, отсутствия достаточного капитала для восстановления, неудачного опыта взаимодействия с органами государственного управления, проблем инфраструктуры, близорукого мышления и отсутствия организационной культуры и доступа к техническим ноу-хау для решения проблемы предполагаемого воздействия риска. 
Таким образом, можно сделать вывод, что организациям малого и среднего бизнеса необходимо сформировать комплексный подход к формированию и развитию систем управления владельческими рисками для снижения рисков.

Традиционно управление рисками фокусируется на сокращении возможных потерь от рисковых событий, в то время как управление владельческими рисками поощряет руководство к выявлению рисков как возможностей получения собственной выгоды, так и возможностей неблагоприятного воздействия.

Предлагаемая авторами концепция управление владельческими рисками состоит из восьми взаимосвязанных компонентов, которые должны быть интегрированы в процесс управления организацией. Взаимосвязанные элементы объясняются ниже:

Внутренняя среда: внутренняя среда включает в себя основную философию предприятия, которая влияет на осознание риска его рабочей силы и формирует основу для управления рисками предприятия. Он включает дисциплину и кодекс поведения. Внутренняя среда, таким образом, содержит убеждения в управлении рисками учреждения; это аппетит к риску; ответственность владельцев и менеджеров; целостность, этические ценности, способность своих сотрудников; то, как руководство распределяет обязанности, полномочия, обязанности и заботится о своих людях.

Постановка задач: каждая организация сталкивается с широким спектром рисков как из внутренних, так и из внешних источников, и поэтому установление четких целей становится необходимым условием для эффективного выявления событий, оценки рисков и реагирования на риски. Цели должны быть установлены на стратегическом уровне, включая цели и задачи, предназначенные для операций и соблюдения полноты отчетности. Цели должны быть приведены в соответствие с аппетитом организации к риску, который стимулирует толерантность к риску в организации.

Идентификация событий. Руководство должно распознать возможные события, которые, если они произойдут, повлияют на организацию, а затем сделать вывод о том, являются ли эти события примером перспектив или они могут негативно повлиять на способность организации эффективно осуществлять стратегию и достигать целей. События с неблагоприятным воздействием представляют собой риски, которые требуют оценки и реагирования со стороны владельца и менеджеров. События, оказывающие позитивное воздействие, олицетворяют возможности, которые владелец и менеджеры должны использовать в своей стратегии и процедурах постановки целей.

Оиенка риска: оценка риска помогает организации оценить, насколько вероятные события повлияют на достижение целей. Управление оценивает события с двух точек зрения: вероятность возникновения и эффект, который оно создаст. Обычно для оценки используется сочетание качественных и количественных методов. Риски измеряются как на встроенной, так и на остаточной основе. Положительные и отрицательные последствия потенциальных событий должны быть тщательно изучены, по отдельным аспектам и по группам, а также по всей организации.

Реакциия на риск: после оценки соответствующих рисков владелец и менеджеры определяют, как оно будет реагировать на них. Ответные меры могут состоять из уклонения от рисков, минимизации рисков, распределения рисков и принятия рисков. Прежде чем завершить подготовку ответа, владелец и менеджеры оценивают последствия ответа с точки зрения: вероятности и воздействия, анализа затрат и выгод, возможности создания остаточного риска. Владелец и менеджеры также пытаются определить любую возможность, которая может существовать, и формулирует общеорганизационное мнение о риске, чтобы решить, входит ли общий остаточный риск в желании организации к риску.

Контрольная деятельность. Контрольная деятельность включает руководящие принципы и процессы, обеспечивающие эффективное реагирование владельца и менеджеров на риски. Контрольные мероприятия проводятся по всей организации, на всех уровнях и во всех функциях. Они включают в себя широкий спектр видов деятельности, таких, как различные разрешения, санкции, удостоверения подлинности, расчеты, оценки операционной деятельности, безопасность активов и классификация и распределение обязанностей и ответственности.

Информация и коммуникации. Соответствующая информация должна быть сформирована передана в соответствующие подразделения организации в порядке и сроки, которые позволяют сотрудникам организации выполнять 
свои задачи. Информационная система получает данные как из внутренних, так и из внешних источников, предоставляет необходимую информацию для управления рисками и принятия обоснованных решений. Эффективная коммуникация происходит только тогда, когда есть свободный поток информации сверху вниз, снизу вверх и по всем отделам. Необходимо, чтобы все сотрудники понимали свою роль в управлении рисками предприятия, а также то, как их индивидуальная деятельность связана с работой других. Необходимо также наладить эффективную связь с внешними сторонами, такими, как клиенты, поставщики, должностные лица государственных органов власти.

Мониторинг. Управление рисками на предприятии может осуществляться посредством постоянного мониторинга и оценки. Постоянный контроль обычно осуществляется в ходе обычной управленческой деятельности. Масштабы и периодичность проведения отдельных оценок главным образом определяются оценкой рисков и эффективностью текущих процессов и методов мониторинга. О любых недостатках в процедурах необходимо сообщать высшему руководству и совету директоров.

В отличие от крупных корпораций, где принятие решений основано на чистой аналитике и объективности, принятие решений в малых и средних предприятиях в основном основано на субъективности и суждении собственников-менеджеров. Препятствия для успеха малых и средних предприятий многочисленны и разнообразны, и включают в себя неотъемлемые организационные препятствия, такие как низкий уровень образования, отсутствие подготовки и плохие управленческие навыки; «провалы рынка», такие как плохой доступ к рынку, жесткая конкуренция и неспособность предпринимателя понять рыночные ожидания; и экономические экологические вопросы, такие как инфляция, рецессия и т.д. В малых средних предприятия основная ответственность за управление бизнес-процессами и оценку потенциальных рисков лежит на владельцах-менеджерах. При этом незнание владельцами-менеджерами малых и средних предприятий основных видов потенциальных рисков и инструментов для измерения и минимизации этих рисков обычно ограничивает методы управления рисками избеганием риска и передачей риска через страховые покрытия.

Большинство видов деятельности, связанных с риском, как правило, понимаются как реагирующие, что снижает способность имеющихся ресурсов снижать риск. Внедряя структурированный подход к управлению владельческими рисками предприятия в рамках повседневной деятельности малых и средних предприятий, можно реализовать такие потенциальные преимущества, как снижение общих рисков, минимизация возможных потерь, снижение затрат, организационное согласование с миссией и целями. Для того чтобы начать рациональное управление владельческими рисками, малые и средние предприятия в первую очередь должны быть осведомлены о существующих проблемах, с которыми сталкиваются аналогичные предприятия как на национальном, так и на международном уровне. Это станет основой сознательно спланированной и системной практики управления рисками, которая выходит далеко за рамки существующих механизмов.

В заключении важно отметить, что развитие систем управления владельческими рисками создает конкурентное преимущество, особенно во время кризиса, поскольку оно помогает определить прибыльные перспективы и неизбежные опасности, а также способствует улучшению системы управления организацией. Благодаря эффективной идентификации, оценке и смягчению рисков в рамках систем управления владельческими рисками малые и средние предприятия могут раскрыть ценный потенциал риска и создать конкурентное преимущество, неизбежность, безопасность, эффективность, гибкость, уверенность в себе и создать ценность. Целостная интеграция систем управления владельческими рисками с концепцией, миссией, целями и деятельностью малых и средних предприятий, несомненно, приведет к их долголетию и устойчивому развитию.

\section{Библиографический список}

1. Miede Andre. A Generic Metamodel for IT Security - Attack Modeling for Distributed Systems. Germany. 2017.

2. Ayse Kucuk Yilmaz, Triant Flouris. Managing corporate sustainability: Risk management process based perspective// African Journal of Business Management. 2017.Vol.4 (2). 
3. Варагина А.Е. Исследование роли малого и среднего бизнеса в России // Молодой ученый. 2018. № 24. C. 119-124. URL https://moluch.ru/archive/210/51512/ (дата обращения: 02.10.2018).

4. Кличева Е.В. Реинжиниринг бизнес-процессов как инструмент повышения конкурентоспособности предприятий ресторанного бизнеса в современных рыночных условиях//В сбор. Инновации: перспективы, проблемы, достижения Материалы Пятой Международной научно-практической конференции. 2017. С. 352357.

5. Кличева Е.В. Обеспечение финансовой безопасности ресторанного бизнеса //В сбор. Обеспечение финансовой безопасности России. Москва, 2016. С. 221-225.

6. Ц Цитата по материалам сайта Росстата - www.gks.ru (дата обращения 02.10.2018) 